\title{
STRUCTURAL AND SEMICONDUCTING PROPERTIES OF ZnTe THIN FILMS GALVANOSTATICALLY GROWN ONTO MONOCRYSTALLINE InP SUBSTRATE FROM TeCl 4 /DMSO SOLUTION.
}

\author{
P. GREZ ${ }^{1}$, R. HENRÍQUEZ', E.A. DALCHIELE ${ }^{2}$ AND H.GÓMEZ
}

\begin{abstract}
${ }^{1}$ Instituto de Química, Facultad de Ciencias Básicas y Matemáticas, Pontificia Universidad Católica de Valparaíso, Casilla 4059, Valparaíso, Chile. ${ }^{5}$ Instituto de Física, Facultad de Ingeniería, Herrera y Reissig 565, C.C. 30, 11000 Montevideo, Uruguay
\end{abstract}

(Received 27 $7^{\text {th }}$ March 2007 - Accepted $12^{\text {th }}$ June 2007)

\begin{abstract}

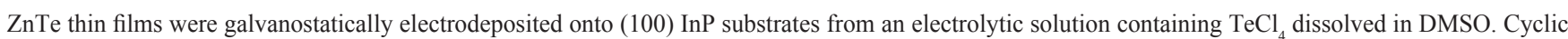
voltammetry in the dark was used to identify the process involved in the complex electrochemical reduction of the Te(IV) precursor. Quantitative analysis of energy dispersive $\mathrm{x}$-ray analysis results indicated that the composition ratio $(\mathrm{Zn}: \mathrm{Te})$ was not possible to determine due the presence of a tellurium excess in the deposits. X-ray diffraction results revealed that the thin films obtained showed a preferred (200) orientation with cubic structure indicating the existence of an epitaxial grow along the (100) crysytalline planes of the InP substrate. The n-type character of the films was deduced from Mott-Schottky plots that also gave a donor density of $1.54 \times 10^{+18} \mathrm{~cm}^{-3}$. From the optical absortion measurements a bandgap of $2.21 \mathrm{eV}$ was obtained.
\end{abstract}

Key words: ZnTe, electrodeposition, semiconductors.

\section{INTRODUCTION}

Zinc telluride is a wide-gap II-VI compound semiconductor which has shown great potential for optoelectronic device applications such as lightemmiting devices ${ }^{1-2}$, Thz detectors ${ }^{3}$ and window material for CdTe-based solar cells. Various techniques have been reported for the fabrication of ZnTe thin films, such as thermal vacuum evaporation ${ }^{5}$, vapor-phase epitaxy ${ }^{6}$, molecular beam epitaxy ${ }^{7}$, and electrochemical deposition ${ }^{8-13}$. ZnTe has usually been electrodeposited at a relatively negative potential, which indicates that hydrogen evolution reaction is also produced, reducing the current efficiency of the electrochemical process. In order to achieve higher efficiency, either a higher $\mathrm{pH}$ or more positive electrodeposition potential can be employed. The use of a nonaqueous solvent, such as ethylenglycol for ZnTe or DMSO for $\mathrm{Ag}_{2} \mathrm{Te}$ electrodeposition is an alternative approach for avoiding this problem 8, 14. The aim of current paper is to explore the possibilities of using a DMSO bath for the galvanostatic electrodeposition of $\mathrm{ZnTe}$ on monocrystalline InP substrates. As elemental tellurium has a low solubility in this solvent, $\mathrm{TeCl}_{4}$ was employed as tellurium precursor which revealed a complex voltammetric behavior. A set of electrochemical and chemical reactions, including the electroprecipitation of the films, is proposed to reasonable interpret the overall processes involved.

\section{EXPERIMENTAL}

The zinc telluride films were electrodeposited on n-type (100) InP substrates using a plating solution containing $100 \mathrm{mM} \mathrm{LiCl}$ (Aldrich, $99.99+$ $\%$ ), $100 \mathrm{mM} \mathrm{ZnCl}_{2}$ (Aldrich, $99.999 \%$ ) and $0.5 \mathrm{mM} \mathrm{TeCl}_{4}$ (Merck,) dissolved in Dimethyl sulfoxide (DMSO) was used without further purification. The InP working electrodes were cleaned for $10 \mathrm{~min}$ in boiling ketone, $3 \mathrm{~min}$ in boiling methanol, $3 \mathrm{~min}$ in cold methanol, then $20 \mathrm{~s}$ in a $0.2 \% \mathrm{Br}_{2} /$ methanol solution and finally rinsed with deionized water. Before each measurement the working electrode was rinsed with $3 \mathrm{M} \mathrm{H}_{2} \mathrm{SO}_{4}$ and then with deionized water. The electrochemical cell was immersed in a silicone bath at a temperature of 118 $\pm 1^{\circ} \mathrm{C}$. The electrodeposition process was performed galvanostatically, using $\mathrm{Ag} / \mathrm{AgCl}$ and platinum wire as a reference electrode and counter electrode, respectively. All the potentials are expressed versus $\mathrm{Ag} / \mathrm{AgCl}$. After deposition the substrate was removed from the electrolyte and rinsed with deionized water, and then dried with a stream of argon gas.

Cyclic voltammetry, impedance, and galvanostatic measurements were carried out using an IM6e Potentiostat/Galvonostat (Bas - Zahner) in unstirred solutions in the darkness. The film structures were characterized by X-ray diffraction. The spectra were recorded with a Philips PW3710 diffractometer using $\mathrm{CuK}$ radiation. The accelerating voltage was set at $40 \mathrm{KV}$ with a 25 $\mathrm{mA}$ flux. Scatter and diffraction slits of $1^{\circ}$ and $0.1 \mathrm{~mm}$ collection slit were used. A JEOL 5900 LV SEM apparatus was used to image and characterize the ZnTe films by scanning electron microscopy (SEM). Chemical composition of the ZnTe samples was obtained by energy dispersive X-ray analysis (EDAX). This was done with the use of a THERMO NORAND VANTAGE (with a NORVARD window) device which is in the same equipment that was employed for obtaining the SEM images.
Optical transmission measurements on $\mathrm{SnO}_{2}: \mathrm{F}$ (FTO) covered glass substrates were carried out using a SHIMAZDU UV-160 A double beam spectrophotometer. Spectra were recorded at room temperature against air as a reference.

\section{RESULTS AND DISCUSSION.}

- Voltammetry behaviour of the $0.1 \mathrm{M} \mathrm{LiCl,} 0.1 \mathrm{M} \mathrm{ZnCl}_{2}, 0.5 \mathrm{mM}$ $\mathrm{TeCl}_{4}$, DMSO solution.

In an earlier report Pandey et al. ${ }^{15}$ studied the thermodynamic and kinetic behaviour of tellurium deposition from $\mathrm{TeCl}_{4}$ solution in ethylen glycol. Following their interpretation, for tellurium electroreduction in DMSO current contribution $\mathrm{C}_{1}$ (see Fig. 1) can be related to the charge transfer reaction:

$$
\mathrm{Te}^{4+}+4 \mathrm{e}^{-} \rightarrow \mathrm{Te}
$$

Following the negative scan, tellurium reduction takes place in the potential domain of peak $\mathrm{C}_{2}$ according to:

$$
2 \mathrm{Te}+2 \mathrm{e}^{-} \rightarrow \mathrm{Te}_{2}^{2-}
$$

$\mathrm{Te}_{2}^{2-}$ ions can react with $\mathrm{Zn}^{2+}$ through the precipitation reaction

$$
\mathrm{Zn}^{2+}+\mathrm{Te}_{2}^{2-} \rightarrow \mathrm{ZnTe}_{2}
$$

However, $\mathrm{ZnTe}_{2}$ may undergo the disproportion reaction,

$$
\mathrm{ZnTe}_{2} \rightarrow \mathrm{ZnTe}+\mathrm{Te}
$$

It is highly probably that the excess of tellurium found in the EDAX analysis of the deposits be originated by this reaction (vide infra). Following the potential excursion, the wide current contribution indexed as $\mathrm{C}_{3}$ involves two processes attributed to reactions:

$$
\begin{aligned}
\mathrm{Te}+\mathrm{Zn}^{2+}+2 \mathrm{e}^{-} & \rightarrow \mathrm{ZnTe} \\
\mathrm{Te}^{4+}+\mathrm{Zn}^{2+}+6 \mathrm{e}^{-} & \rightarrow \mathrm{ZnTe}
\end{aligned}
$$




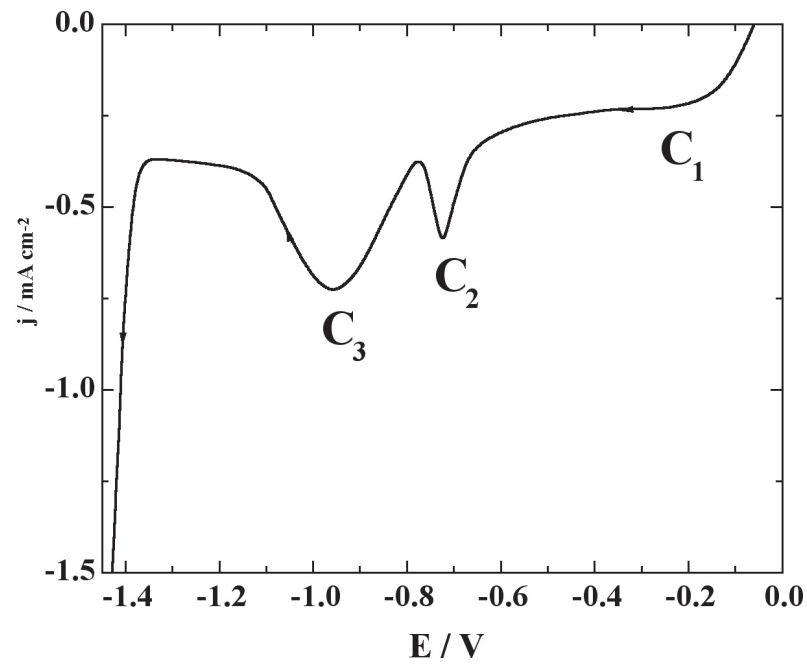

Fig. 1 Cathodic hemicycle recorded onto $\mathrm{n}-\operatorname{InP}(100)$ of the system 0.1 $\mathrm{M} \mathrm{LiCl}+0.1 \mathrm{M} \mathrm{ZnCl}_{2}+0.5 \mathrm{mM} \mathrm{TeCl}_{4}$, in DMSO. $v=0.05 \mathrm{Vs}^{-1} . \mathrm{T}=115^{\circ} \mathrm{C}$, in the static hydrodynamic conditions.

Equation (5) accounts for ZnTe formation through an electroprecipitation reaction at the interface whereas reaction (6) corresponds to the direct six electron reduction of $\mathrm{Te}^{4+}$. As a consequence of the overpotential associated to the presence of a $\mathrm{ZnTe}$ semiconducting layer that already coats the InP substrate, making more difficult the corresponding charge transfer reaction, the latter process appears shifted towards more negative potentials. Finally, the potential scan ends with a great current increase which is related to the massive electroreduction of zinc ions to metallic zinc.

\section{-Galvanostatic ZnTe electrodeposition.}

Figure 2 show; the E/t transients for the deposition of ZnTe on $n-I n P$ (100) substrates at different current densities. It is observed that independent on the applied current density, the final potential remains fixed around $-1.3 \mathrm{~V}$. This high value can be explained considering that at shorter times starts the sequence of reactions (1) to (6), producing the fast formation of a $\mathrm{ZnTe} / \mathrm{Te}$ semiconducting layer which acts as a barrier that increases the resistance to the charge transfer at the interface.

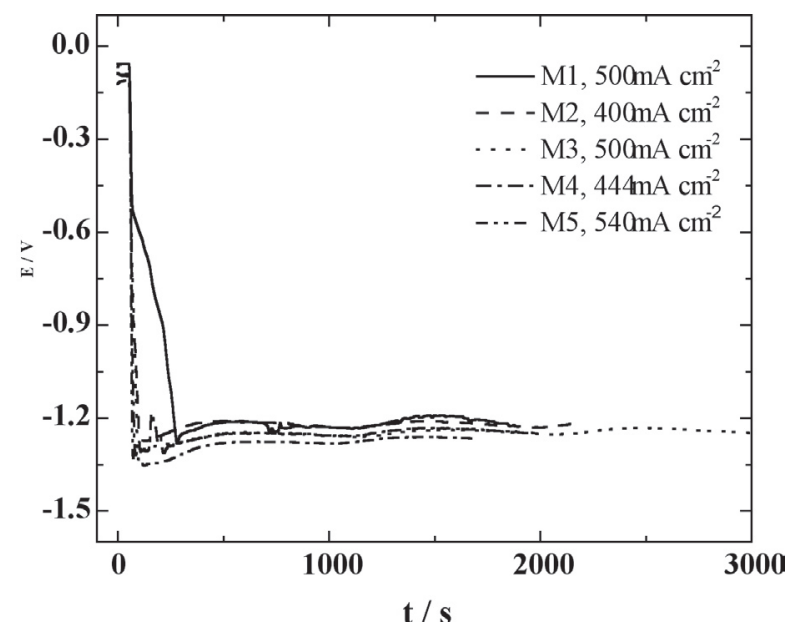

Fig. 2 E/t Transients for the constant current $\mathrm{ZnTe}$ electrodeposition recorded in the dark in unstirred $0.1 \mathrm{M} \mathrm{LiCl}, 0.1 \mathrm{M} \mathrm{ZnCl}_{2}, 0.5 \mathrm{mM} \mathrm{TeCl}_{4}$ in DMSO solution.

Table 1 presents the current densities that were applied in order to obtain deposits of different thickness together with the estimated thickness calculated from the charge involved in the E/t transients considering an overall 6 electron process. It is necessary to point out, that as the $\mathrm{ZnTe}$ formation is produced through electroprecipitation, it is probably that the thickness is over estimated. In fact, the growth of the film on the electrode surface can be controlled by two nucleation processes: heterogeneous and homogeneous. According to the kinetics of each reaction (1) to (6), the process of heterogeneous nucleación on the electrode surface can take place when the concentrations of the ions $\left(\mathrm{Zn}^{2+}, \mathrm{Te}_{2}^{2-}\right.$ and $\left.\mathrm{Te}^{2-}\right)$ approach to the over-saturation conditions. The charge involved in the processes (see Fig. 1) indicates that this condition was surpassed promoting the homogeneous nucleation outside of the interface electrode/ solution. This affects directly to the final thickness of the film as well as the Faradic yielding of the overall process.

Table 1.- Current densities and calculated thickness for the galvanostatic electrodeposition of $\mathrm{ZnTe}$ on InP substrates

\begin{tabular}{|c|c|c|}
\hline Sample & $\mathrm{j} / \mu \mathrm{A} \mathrm{cm}^{-2}$ & $\begin{array}{c}\text { Calculated thickness } \\
\mathrm{d} / \mu \mathrm{m}\end{array}$ \\
\hline M1 & 500 & 0.5 \\
\hline M2 & 400 & 0.5 \\
\hline M3 & 500 & 1.0 \\
\hline M4 & 444 & 0.5 \\
\hline M5 & 540 & 0.5 \\
\hline
\end{tabular}

Table 2.- $\mathrm{Zn}$ and $\mathrm{Te}$ atomic percentage and $\mathrm{Zn}: \mathrm{Te}$ ratios

\begin{tabular}{|c|c|c|c|}
\hline Sample & Zn atomic \% & Te atomic \% & Zn:Te \\
\hline 1 & 1.18 & 2.27 & $1: 1.9$ \\
\hline 2 & 4.34 & 20.10 & $1: 4.4$ \\
\hline 4 & 2.52 & 17.96 & $1: 7.1$ \\
\hline 5 & 8.98 & 19.14 & $1: 2.1$ \\
\hline
\end{tabular}

The composition of the samples, analyzed by EDAX, is depicted in Table 2 . The analysis of the data reveals a great variation in the composition of both components, therefore no defined stoichiometry can be accurately stablished. A possible explanation for this behaviour is the presence of a variable amount of tellurium excess (clear coloration) in the SEM micrographes shown in figure 3. This implies that in the region of the surface selected for X-ray analysis is practically impossible to determine the exact atomic $\mathrm{Zn}: \mathrm{Te}$ ratio. This, however, was not an obstacle for the further characterization of semiconducting properties of the films (vide infra).

\section{1}

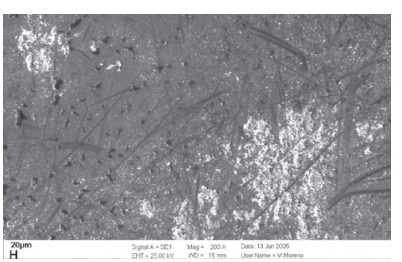

M 5

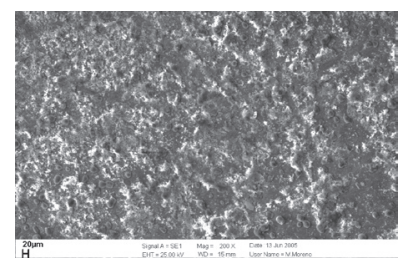

Fig. 3.- SEM micrographs for simples grown at $500 \mu \mathrm{A} \mathrm{cm} \mathrm{cm}^{2-}$ (M 1) and at $540 \mu \mathrm{A} \mathrm{cm}^{2-}$ (M 5).

\section{- Structural and optical Characterization.}

The structural XRD analysis of samples grown at different current densities and shown in figure 4 revelead a number of peaks corresponding to the InP substrate, as well as to $\mathrm{ZnTe}$ and Te. The location and intensity of Te peaks depends on the current densities values. The only reflection of the $\mathrm{ZnTe}$ was observed at $2 \theta=31.81^{\circ}$ corresponding to the (200) reflection of the closed packed cubic structure, which is a little more intense for the film grown at 500 $\mu \mathrm{A} \mathrm{cm}{ }^{2-}$. In spite that the peak is not strong, the presence of the (200) plane, parallel to the (100) reveals some epitaxial character of the film. 
A
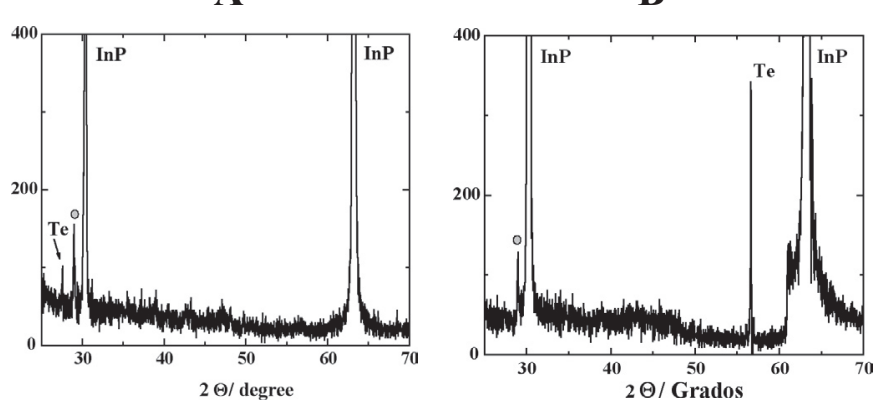

Fig. 4.- XRD spectra of $\mathrm{ZnTe}$ (o) films grown at: (A) $500 \mu \mathrm{A} \mathrm{cm} \mathrm{cm}^{2-}$ and (B) $540 \mu \mathrm{A} \mathrm{cm}^{2-}$.

The optical absorption spectrum of the ZnTe film was used to determine the optical bandgap. From the calculated values of the absorption coefficients, a straight line plot of $(\dot{\alpha} h v)^{2}$ versus $h v$ was obtained, as shown in figure 5, indicating a direct transition at the fundamental absorption edge. From the interpolation of this plot a value of $2.21 \mathrm{eV}$ for the bandgap of the $\mathrm{ZnTe}$ film was determined. This values agrees with that reported in the literature ${ }^{16}$.

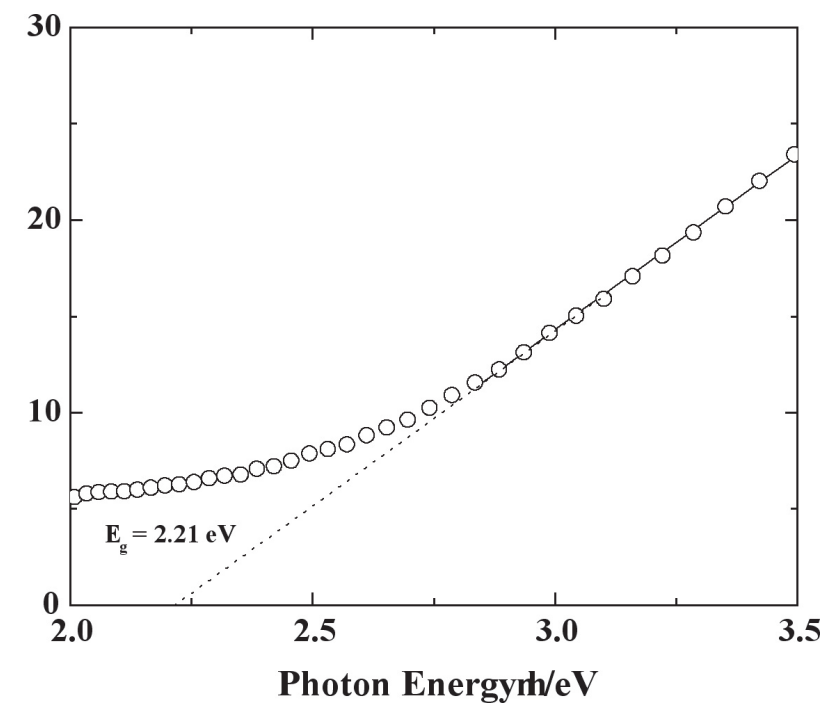

Fig. 5.- $(\alpha l h v)^{2}$ vs. hv plots calculated from characteristic transmission spectra of $\mathrm{SnO}_{2}: \mathrm{F} / \mathrm{ZnTe}$ interface for the sample grown at $500 \mu \mathrm{A} \mathrm{cm} \mathrm{cm}^{2-}(\mathrm{M}$ 1).

In order to determine some characteristic semiconductor parameters of the ZnTe films, the variation of the interfacial capacitance with potential was extracted from impedance measurements at high frequence assuming a simple parallel RC equivalente circuit. The corresponding experimental data were recorded as a classical Mott-Schottky plots that is shown in figure 6 for sample M3, together with that for the InP substrate as comparison. The positive slope means that the the substrate and the grown film present both a n-type electrical conductivity. The donor density, $\mathrm{N}_{\mathrm{D}}$, determined from the slopes of the plots give $\mathrm{N}_{\mathrm{D} Z \mathrm{nTe}}=1.54 \times 10^{+18} \mathrm{~cm}^{-3}$ and $\mathrm{N}_{\mathrm{D} \text { InP }}=1.60 \times 10^{+18} \mathrm{~cm}^{-3}$, values that are typical of extrinsic doped semiconductors. Finally, the extrapolation of the straight line to $1 / \mathrm{C}^{2}=0$ gives for $\mathrm{ZnTe}$ a flat band potential, $\mathrm{V}_{\mathrm{fb}}=-0.474 \mathrm{~V}$ vs $\mathrm{Ag} / \mathrm{AgCl}$. In general, $\mathrm{V}_{\mathrm{f}}$ is an important quantity for semiconductor electrodes that are employed in photoelectrochemical applications because it determines the band edge position at the semicondcutor-electrolyte interface, which in turn, determine the energies of the conduction-band electrons and valenceband-holes reacting with the electrolytic solution.

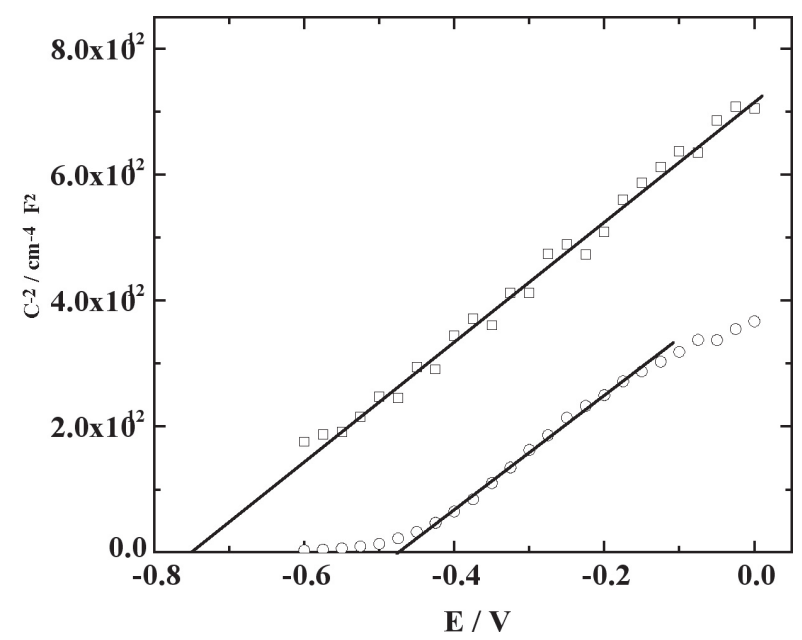

Fig. 6.- Mott - Schottky plots for $\mathrm{ZnTe}$ and InP recorded in the darkness using an acetate buffer $(\mathrm{pH}=4.50)$ at room temperature without stirring. $\mathrm{f}=$ $100 \mathrm{KHz}$.

\section{CONCLUSIONS}

ZnTe has been succesfully prepared by single step galvanostatic electrodeposition onto n-type (100) InP substrates from a solution containing $\mathrm{TeCl}_{4}$ dissolved in DMSO as tellurium precursor. The presence of a Xray diffraction peak correspondintg to the (200) crystalline plane in the as grown films revelead the presence of epitaxy along the (100) plane of the monocrystalline substrate. The qualities of the films were evidenced by the donor number and the bandgap values, both coincident with those reported in the literature. The only constraint was the presence of a tellurium excess that could be easily eliminated by annealing in an air stream.

\section{ACKNOWLEDEGEMENTS}

This work has been funded by FONDECYT, grant $\mathrm{N}^{\circ} 1040650$.

\section{REFERENCES}

1. J. Gu, K. Tonomura, N. Yoshikawa, J. Appl. Phys. 44 (1973) 4692.

2. K. Sato, M.Hanafusa, A. Noda, A. Arakawa, T. Asahi, M. Uchida, O. Oda, IECE Trans. Electron E83-C (2000) 579.

3. C. Winnewiser. P.U. Jensen, M. Schall, V. Schiyja, H. Helm, Appl. Phys. Lett. 70 (1997) 3069.

4. J.M. Pawlikoswski, Thin solid Films 127 (1985) 39.

5. K.U. Raju, R.P. Vijalayakshmi, R. Venugopal, D.R. Reddy, B. Reddy, Matter. Lett. 13 (1992) 336.

6. M.H.R. Khan, J. Phys. D: Appl. Phys. 27 (1994) 2190.

7. W.I. Tao, M. Jurkovice, I.W. Wang, Appl. Phys. Lett. 64 (1994) 1848.

8. N.B. Chaure, R. Jayakrishnan, J.P. Nair, R.K. Pandey, Semicond. Sci. Technol. 12 (1997) 1171.

9. M.c. Lin, P.Y. Chen, I.W. Sun, J. Electrochem. Soc. 148 (2001) C653.

10. B.Bozzini, M.A. Baker, P.L. Cavalloti, E. Cerri, C.Lenardi, Thin Solid Films, 361(2000) 388

11. G. Riveros, H. Gómez, R. Henríquez, R. Schrebler and R. Córdova. Bol. Soc. Chil. Quim. 47(2002) 411.

12. T. Ishizaki, T.Ohtomo, A. Fuwa, J. Phys. D: Appl. Phys. 37 (2004) 255.

13. T. Ishizaki, N. Saito, O. Takai, S. Asakura, K. Goto, A. Fuwa, Electrochim. Acta 50 (2005) 3509.

14. R. Chen, D. Xu, G. Guo, L. Gui, Electrochim. Acta 49 (2004) 2243.

15. R.K.Pandey, S. Maffi and L.P.Bicelli, Mater. Chem. Phys. 35 (1993) 15.

16. Berger, L. I. In Semiconductor Materials; CRC Press Eds.; California, 1996. pp. $187-198$ and $411-447$. 